\title{
Cadaver Wrapping and Arrival Performance of Adult Flies in an Oil Palm Plantation in Northern Peninsular Malaysia
}

\author{
AZWANI AHMAD, ${ }^{1}$ ABU HASSAN AHMAD,${ }^{1}$ HAMADY DIENG,${ }^{1,2}$ TOMOMITSU SATHO, ${ }^{3}$ \\ HAMDAN AHMAD, ${ }^{1}$ AL THBYANI AZIZ, ${ }^{1}$ AND MICHAEL BOOTS ${ }^{4}$
}

J. Med. Entomol. 48(6): 1236-1246 (2011); DOI: http:// dx.doi.org/10.1603/MI10247

\begin{abstract}
There is accumulating evidence that criminals wrap dead bodies in an attempt to conceal evidence. To anticipate the forensic implications of this phenomenon, we examined whether flies that are naturally associated with cadavers exhibit a delay in attendance or differ in species composition and abundance patterns because of the presence of wrapping material. Wrapped and exposed carcasses of dead monkeys placed in an oil plantation in Kedah, Malaysia, were visited over $50 \mathrm{~d}$. On daily visits to each of the six carcasses, visiting adult flies were sampled using hand nets. Flies of 12 families were encountered. Calliphoridae (Chrysomya rufifacies Macquart and C. megacephala (F.) was the most prevalent family, followed by Sphaeroceridae. Some families tended to be more abundant in WRCs (i.e., Calliphoridae, Muscidae, and Phoridae), whereas others (i.e., Piophilidae, Sepsidae, and Psychodidae) were more prevalent in exposed carcasses. Wrapping delayed the arrival of all fly species encountered, with delays varying from 1 to $13 \mathrm{~d}$ depending on species. Wrapping did not affect species composition of flies, but prolong the occurrence of some species. The results of the current study emphasize the need to take into consideration the presence of a wrap when estimating postmortem interval.
\end{abstract}

KEY WORDS monkey carcass, wrapping, flies, colonization, oil palm plantation

Observation and measurement of body conditions, that is, core body temperature (Nelson 1999), muscular flaccidity, rigor mortis, lividity, skin pallor, and so forth (Smith 1986, Bass 2001, Byrd and Castner 2001), used to be the primary strategies for determining postmortem interval (PMI). These still are the primary strategies, but use of insect evidence is becoming increasingly more common. Although PMI estimation is sometimes accurate, crime resolution based on these strategies is considered insufficient. Another strategy referred to as medicocriminal entomology has been proposed as a strategy for determining the time of death (Gordh and Headrick 2001). This strategy, which relies on insect succession on decomposing human corpses or the thermally driven development of blow flies, was reported to be more accurate than some other methods used in medicolegal death investigations (Kashyap and Pillay 1989, Catts and Haskell 1990, Anderson 2001, Villet et al. 2010).

After death, the body undergoes a decomposition process, which creates a number of habitats and conditions conducive to a variety of organisms. In fact, a decomposing body is colonized by different insects,

\footnotetext{
${ }^{1}$ School of Biological Sciences, Universiti Sains Malaysia, Penang, Malaysia.

${ }^{2}$ Corresponding author, e-mail: hamachan1@yahoo.com.

${ }^{3}$ Faculty of Pharmaceutical Sciences, Fukuoka University, Fukuoka, Japan.

${ }^{4}$ Department of Animal and Plant Sciences, University of Sheffield, Sheffield, United Kingdom.
}

and the arrival of a given insect species is associated with a specific stage of decomposition (Nuorteva 1977, Smith 1986). Several species of fly, including calliphorids (Hall and Doisy 1993, Martin et al. 1996) and sarcophagids, have been found as larvae in human corpses. In particular, calliphorids have been reported to be extremely fast in colonizing human corpses (Watson and Carlton 2003), suggesting increased oviposition responsiveness. The visual properties of a dead body habitat where their larvae develop (Wall et al. 1992, Hall et al. 1995) have been shown to be important signals that gravid flies must take into account in oviposition site choice. During decomposition of a dead body, the soft tissues are anaerobically metabolized by bacteria and other microorganisms anaerobically metabolize, which leads to their catabolism into gazes of which release increased pressure and thus bloating (Vass 2001). These gases which include hydrogen sulfide, carbon dioxide, methane, cadaverine, ammonia, sulfur dioxide, hydrogen, and putricine emit a smell that is attractive to flies (Carloye and Bambara 2006). Blow flies were not found on wrapped pig carcasses $60 \mathrm{~h}$ after exposure (Goff 1992). It is likely that there is a close relationship between the visual properties of the dead body habitats and the availability of egg deposition sites.

Forensic entomologists often deal with dead bodies under various conditions. Dead bodies are usually concealed by criminals in an attempt to conceal the evidence. Previous reports indicated that dead bodies 